\title{
Research Article \\ Effects of Particle Shapes and Sizes on the Minimum Void Ratios of Sand
}

\author{
Zhaoyang Xu $\mathbb{D}$, Ning Xu $\left(\mathbb{D}\right.$, and Haibo Wang $\mathbb{D}^{\mathbb{D}}$ \\ Institute of Geotechnical Engineering, Yangzhou University, Yangzhou 225127, China \\ Correspondence should be addressed to Zhaoyang Xu; 1043073680@qq.com
}

Received 17 December 2018; Revised 28 February 2019; Accepted 6 March 2019; Published 14 April 2019

Academic Editor: Arnaud Perrot

Copyright (C) 2019 Zhaoyang Xu et al. This is an open access article distributed under the Creative Commons Attribution License, which permits unrestricted use, distribution, and reproduction in any medium, provided the original work is properly cited.

\begin{abstract}
The minimum void ratio is an important parameter for evaluating soil properties. It is closely related to the compressive properties, permeability, and shear strength of soil, and it is affected by particle size distributions and particle shapes. However, existing research generally focuses on modeling the minimum void ratio with the effect of particle size distributions, ignoring the influences of particle shapes on the minimum void ratio. This paper analyzes the influences of particle size distributions and particle shapes on the minimum void ratio using four types of sand and alternative materials. The experiments showed that the minimum void ratio first decreased and then increased with the increase of the fines content. The minimum void ratio reached a minimum value when the proportion of fines content was approximately $40 \%$. The more irregular the particle shapes, the more complicated the contact between particles, the more the void existed between the particles, and the larger the minimum void ratio. Based on the experimental data, a relational model between the minimum value of the minimum void ratio and the particle sizes ratio was derived with binary mixtures of different particle sizes and shapes. This proposed model required only one parameter $T$, which was closely related to the sphericity of the particles, to predict the minimum value of the minimum void ratio with various fines contents. The experiment results showed that the predicted value was very close to the actual measured value.
\end{abstract}

\section{Introduction}

The granular soil is a mixture of particles with different sizes, and the particle size distribution controls the structural form of the soil, which affects the mechanical properties of the soil (e.g., [1-5]). Particle size distributions are widely used in industrial productions such as concrete mixes [6], ceramics processing [7], and powder metallurgy [8]. As an important parameter reflecting the particle size distribution of soil in geotechnical engineering, the minimum void ratio $\left(e_{\min }\right)$ is closely related to the compressive properties, permeability, and shear strength of soil.

It is generally accepted that the fines content is the main factor affecting $e_{\min }$ [9-14]. Kezdi [15] proposed an analytical method for estimating $e_{\min }$ of a mixture of two particle sizes, but this method is only suitable for fillers with very small particles.

Cubrinovski and Ishihara [16] proposed a set of empirical equations for the effect of fines content on $e_{\min }$ by analyzing a large amount of test data for silt. Chang et al. [17-19] established a model with only two parameters to predict $e_{\min }$ of sand-silt mixtures with a dominant particle structure network concept. This model reflected a close correlation between particle size and $e_{\min }$. The Furnas model [20] is only suitable for estimating the packing density of binary powder compacts, and it has not yet been examined for use with the packing density of sand-silt mixtures with different particle sizes.

It is generally accepted that another important factor is particles shapes, which affect $e_{\min }$ factor and thus affect the shear resistance of granular soils. Using a triaxial compression test of atomized stainless steel powder, Shinohara et al. [21] found that the internal friction angle increased with the increase of the grain edge angle and the initial compactness. Ashmawy et al. [22] analyzed the effect of particle shapes on liquefaction with a reciprocating loading undrained test. Sallam and Ashmawy [23] used the discrete element method to simulate the stress-strain relationship of 
flat and narrow element assemblies with different shapes, and they pointed out that the dilatancy angle was also largely restricted by the particle shapes. Different particle shapes can significantly change the integrity and shear resistance of granular soils [24-28]. Cho et al. [10] and Cherif Taiba et al. [29] already proposed that increasing particle irregularity caused a decrease in the stiffness but a heightened sensitivity to the state of stress.

Scholars have mainly studied the effect of particle size distributions on $e_{\min }$ of soils and proposed corresponding analytical methods to predict $e_{\min }$ for soil mixtures. However, very few studies on the effect of particle shapes on $e_{\min }$ have been carried out. In order to better study the distribution law of $e_{\min }$, four types of sand from different origins were selected, and steel balls [11] and steel cylinder particles were introduced as alternative materials to further analyze the influence of particle shapes and particle size distributions on $e_{\min }$.

\section{Experimental Method and Conditions}

2.1. Sand Used for Experimental Testing. The sand used in the experiment was from four different origins: Nanjing River Sand (abbreviated as NS), Dongting Lake Sand (DS), Yizheng Mountain Sand (YS), and Fujian Standard Sand (FS). The properties of these types of sand are presented in Table 1. The gradation curves of the four types of source sand before and after the compaction test are shown in Figure 1. The grain sizes ranged from $0.075 \mathrm{~mm}$ to $5 \mathrm{~mm}$.

\subsection{Shape Parameters of the Four Types of Source Sand.} To take the influence of the particle shapes into consideration, a large number of representative particles of the four types of source sand were photographed with a Dino-Lite microscope, and then the two-dimensional images were binarized with Photoshop. The binarized images were analyzed with ImageProPlus to get the primary parameters of the particle shapes, such as length $L$ and width $B$. The secondary shape parameters such as the flatness, sphericity, and angularity were calculated using the primary parameters $[30,31]$. The mathematical expressions and the physical meanings of the secondary shape parameters are listed in Table 2.

The two-dimensional microscope image of the DS of the $0.5-1 \mathrm{~mm}$ grain group is shown in Figure 2(a), and the image after binarization is shown in Figure 2(b). The secondary shape parameters of the four types of experimental sand are listed in Table 3.

It could be seen by comparing the parameters from Table 3 that the sequence of the irregularities of the particle shapes from high to low was NS, DS, and FS. YS was not considered for comparison because of its fragility, resulting in the discreteness of the shape parameters.

2.3. Alternative Materials. Steel balls and steel cylindrical particles were used as substitute materials for sand to investigate the effects of particle shapes. The two-dimensional images and shape parameters of the eight particles are shown in Table 3. It should be noted that the grains of $\mathrm{B} 1$ and $\mathrm{C} 1, \mathrm{~B} 2$ and $\mathrm{C} 2, \mathrm{~B} 3$ and $\mathrm{C} 3$, and $\mathrm{B} 4$ and $\mathrm{C} 4$ were equal in volume.
TABle 1: Properties of the four types of source sand.

\begin{tabular}{lcccccc}
\hline Sand & $d_{10}(\mathrm{~mm})$ & $d_{30}(\mathrm{~mm})$ & $d_{60}(\mathrm{~mm})$ & $C_{\mathrm{u}}$ & $C_{\mathrm{C}}$ & $G_{\mathrm{s}}$ \\
\hline NS & 0.13 & 0.23 & 0.76 & 5.85 & 0.54 & 2.64 \\
DS & 0.16 & 0.32 & 0.71 & 4.44 & 0.90 & 2.64 \\
YS & 0.12 & 0.21 & 0.81 & 6.75 & 0.45 & 2.54 \\
FS & 0.13 & 0.22 & 0.80 & 6.15 & 0.47 & 2.62 \\
\hline
\end{tabular}

Note. $C_{\mathbf{u}}=d_{60} / d_{10}, C_{\mathrm{C}}=d_{30}^{2} /\left(d_{60} * d_{10}\right)$, and $G_{s}$ : specific gravities of the solid particles.

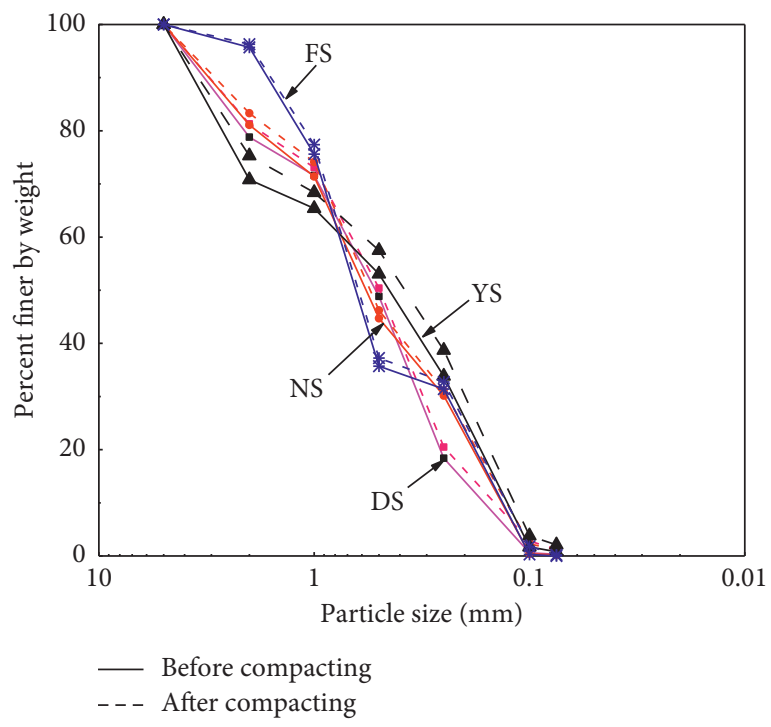

FIgURE 1: Particle size distribution curves of the test materials.

The $e_{\min }$ value of sand is usually converted from the maximum dry density, which is measured using the vibration hammering test method [21]. The vibratory hammering method generally uses two kinds of compaction buckets whose volumes are $250 \mathrm{ml}$ and $1000 \mathrm{ml}$. The two compaction buckets have the same height of $18 \mathrm{~cm}$, but their corresponding inner diameters are $5 \mathrm{~cm}$ and $10 \mathrm{~cm}$. It has been found that the inner diameter of the $250 \mathrm{ml}$ compaction bucket is so small that the energy generated by the hammering is not easily diffused, which makes particles become crushed more easily. Particle breakage will result in a series of obvious changes in the initial properties of sand such as the changes in sand gradation, the increase in maximum dry density, and the decrease in $e_{\min }$. Therefore, the $1000 \mathrm{ml}$ compaction bucket was used in this experiment to minimize particle breakage.

The minimum void ratios of a single particle group for DS, NS, YS, FS, and alternative materials were measured. The minimum void ratios of the binary mixtures were also measured by mixing two different particles under different fines contents.

(1) Measuring the $e_{\min }$ value of single-grain sand

The four types of source sand, i.e., DS, NS, YS, and FS, were screened into five particle groups, with each particle size ranging from $1 \mathrm{~mm}$ to $2 \mathrm{~mm}, 0.5 \mathrm{~mm}$ to $1 \mathrm{~mm}, 0.25 \mathrm{~mm}$ to $0.5 \mathrm{~mm}$, and $0.1 \mathrm{~mm}$ to $0.25 \mathrm{~mm}$. The $e_{\min }$ value of each group was measured to explore the distribution law of $e_{\min }$ of sand under a single particle group. 
TABLE 2: The expressions and descriptions of the secondary shape parameters.

\begin{tabular}{|c|c|c|}
\hline $\begin{array}{l}\text { Secondary shape } \\
\text { parameter }\end{array}$ & Expression & Description \\
\hline Flatness & $e=\frac{L}{B}$ & $\begin{array}{l}\text { Describe the extended properties of the particle, where } L \text { is the dimension along major axis of the } \\
\text { particle plane and } B \text { is the dimension along vertical axis of the spindle. }\end{array}$ \\
\hline Sphericity & $s=\frac{R_{i}}{R_{\mathrm{c}}}$ & $\begin{array}{l}\text { Describe how close the particle comes to the shape of a sphere, where } R_{i} \text { is the maximum radius of the } \\
\text { tangential circle of the particle and } R_{\mathrm{c}} \text { is the minimum radius of the circumferential circle of the particle. }\end{array}$ \\
\hline Angularity & $A_{\mathrm{g}}=\frac{P_{\mathrm{C}}}{P_{\mathrm{E}}}$ & $\begin{array}{l}\text { Describe the number of edges and the degree of protrusion of the surface of the particle, where } P_{\mathrm{C}} \\
\text { is the minimum circumference of an external polygon along the boundary of particles, and } P_{\mathrm{E}} \text { is the } \\
\text { circumference of a standard ellipse with the same area and flatness as particles. }\end{array}$ \\
\hline
\end{tabular}

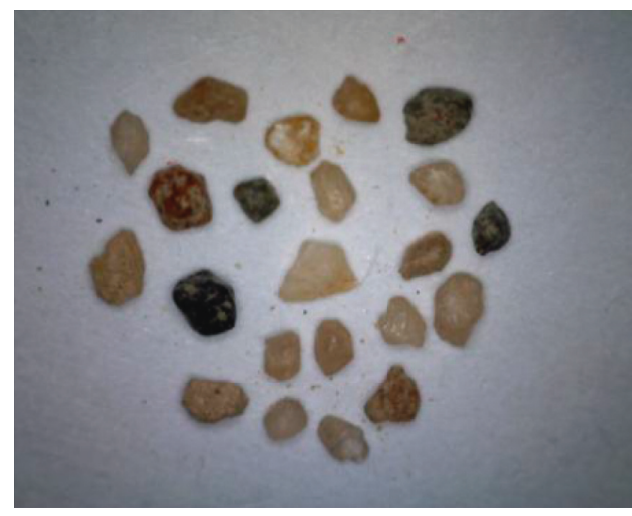

(a)

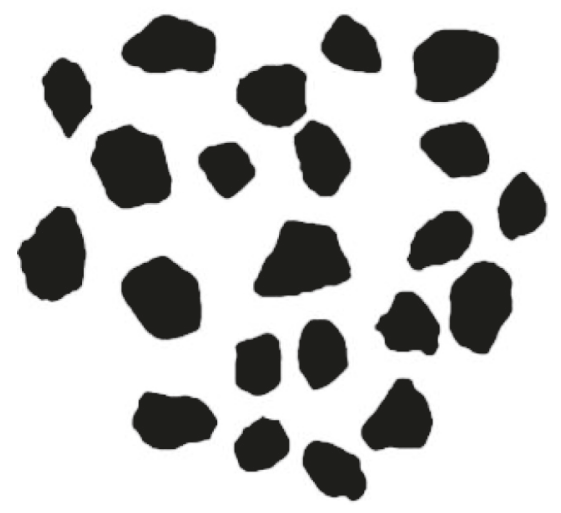

(b)

FIgURE 2: Microscope image and binarized image.

TABLE 3: Shape parameters of the types of source sand.

\begin{tabular}{lccc}
\hline Sand & Flatness & Sphericity & Angularity \\
\hline NS & 1.3755 & 0.5632 & 1.0445 \\
DS & 1.3551 & 0.5687 & 1.0319 \\
FS & 1.3299 & 0.5894 & 1.0286 \\
YS & 1.3189 & 0.6114 & 1.0373 \\
\hline
\end{tabular}

(2) Measuring the $e_{\min }$ value of the binary mixture First, the coarse particles (defined here as particle sizes between $2 \mathrm{~mm}$ and $5 \mathrm{~mm}$ ) were mixed with the fine particles, whose particle sizes ranged from $1 \mathrm{~mm}$ to $2 \mathrm{~mm}, 0.5 \mathrm{~mm}$ to $1 \mathrm{~mm}, 0.25 \mathrm{~mm}$ to $0.5 \mathrm{~mm}$, and $0.1 \mathrm{~mm}$ to $0.25 \mathrm{~mm}$, in different mass ratios. Then the coarse particles (defined here as particle sizes between $2 \mathrm{~mm}$ and $5 \mathrm{~mm}$ ) were mixed with the fine particles whose particle sizes ranged from $0.5 \mathrm{~mm}$ to $1 \mathrm{~mm}$, $0.25 \mathrm{~mm}$ to $0.5 \mathrm{~mm}$, and $0.1 \mathrm{~mm}$ to $0.25 \mathrm{~mm}$ in different mass ratios. Finally, the $e_{\min }$ values of the binary mixtures were measured to investigate the effects of fines content and particle shapes.

(3) Measuring the $e_{\min }$ values of steel balls and steel cylindrical particles

First, the minimum void ratios of the steel balls and steel cylindrical particles were measured. Then the $e_{\text {min }}$ values of the binary mixtures were investigated by mixing two particles of different sizes with the same shapes or different shapes. Finally, the results of the different steel particles and types of sand were compared to verify the laws of $e_{\min }$ of binary mixtures via changing the particle sizes and particle shapes.

\section{Results and Analysis}

3.1. Variation Laws of $e_{\text {min }}$ under Single-Particle Groups. The $e_{\min }$ values of the four types of sand and steel balls of different sizes under single-particle groups were measured. The particles of FS were excluded from the experiment due to the lack of 2-5 $\mathrm{mm}$ particles. According to the experimental data, the relationship between the average particle sizes of the particle group and $e_{\min }$ is shown in Figure 3 . The average particle sizes of each particle group were calculated by taking the average values of the upper and lower grain diameters of the group.

From the geometric model of a single spherical particle, it can be found that $e_{\min }$ is independent of the size of the sphere. However, each group of sand obtained from the screening experiment was not of a certain particle size but rather lay within a particle size range, and the pores between the coarse particles were filled with fine particles. Therefore, the larger the particle size and the larger the difference 


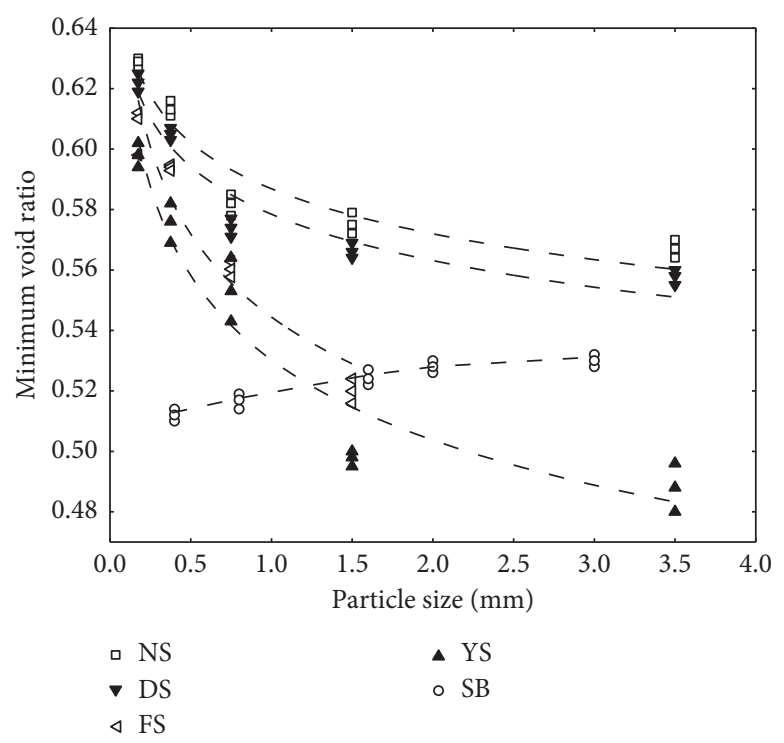

FIGURE 3: The minimum void ratios corresponding to single particle groups of different sand types.

between upper and lower limits of particle sizes in the same group, the easier it was for two particles to fill each other and the smaller the $e_{\min }$ was. Conversely, the variation of $e_{\min }$ of spherical particles with a certain size was the opposite of the above rule. Since the steel balls were of a certain particle size and there was no filling with each other, the void between the spherical particles and the inner wall of the compaction bucket became larger with the increase of the particle sizes, which led to a slight increase in the $e_{\min }$.

It was obvious that the sequence of $e_{\min }$ of single groups from high to low was NS, DS, FS, and YS, as shown in Figure $3 . e_{\min }$ of the first three types of sand (NS, DS, and FS) was closely related to the particle shape, and it tended to decrease as the $S$ value increased. However, the $e_{\min }$ and $S$ values of the YS did not satisfy the above rules. The reason for this phenomenon was that YS was easier to crush during the test. This could be validated by the gradation curve of four types of sand after compaction, as shown in Figure 1. Higher fines content in the YS will result in smaller voids and thus a smaller $e_{\min }$.

3.2. Effects of the Fines Content on the Minimum Void Ratio. $e_{\text {min }}$ of the binary mixtures of the NS, DS, YS, and FS was measured, while the grains in the groups of $2-5 \mathrm{~mm}$ and 1$2 \mathrm{~mm}$ were designated as coarse grains and mixed with other fine grains. Figure 4 shows schematically how $e_{\text {min }}$ varied with the percentage of fines content given by the weight of the mixtures. As the content of fines increased, the $e_{\min }$ value of the binary mixture exhibited a "V"-type tendency of first decreasing and then increasing, and the mixture had a minimum value $\left(e_{\min }\right)_{\min }$.

It can be seen in Figure 4 that all the curves of $e_{\text {min }}$ of fines content had minimum values, and the $e_{\min }$ value first decreased and then increased with the increase of the fines content. Moreover, the value of $e_{\min }$ decreased with the increase of the grain size difference when the percentage of the fines content was approximately between $0 \%$ and $80 \%$ in the binary mixtures (i.e., the curves of the $2-5 \mathrm{~mm}$ and 1 $2 \mathrm{~mm}$ mixtures were above the curves of other mixtures when the fines content was less than approximately $80 \%$ ). However, when the fines content was approximately greater than $80 \%$, the sequence of $e_{\min }$ curves presented a reverse trend with the increase in grain size difference (i.e., the curves of the $2-5 \mathrm{~mm}$ and $1-2 \mathrm{~mm}$ mixtures were below the curves of the other mixtures when the fines content was more than approximately $80 \%$ ).

The reason for this phenomenon is illustrated in Figure 5; with a small amount of fines content, the minimum void ratio decreased as the fines content increased. This occurred because the smaller particles filled the voids among the larger particles. There was a critical value of fines content when the voids among the larger particles were eventually fully occupied, and thus, the minimum void ratio reached a minimum value. After this, the curves showed a reverse trend in which the $e_{\text {min }}$ values decreased as the fines content increased. The reason for this was that smaller particles became dominant in the mixture, while larger particles were embedded into the smaller particles as isolated inclusions. Moreover, the greater the particle size difference, the more easily the fines filled the pores of the coarse particles, and the smaller the $e_{\min }$ values. This occurred when the fines content was approximately less than $80 \%$. After the fines content increased to more than $80 \%$, the entire system was dominated by fines, and thereby the order of curves was the same as that of single particle groups.

3.3. Effects of Particle Shapes on $e_{\text {min }}$. To study the influences of particle shapes on the minimum void ratio, the relationship between the minimum void ratios and the content of fine grains for three different binary mixtures of sand was analyzed, as shown in Figures 6-8.

It can be found in Figures 6-8 that the sequence of the $e_{\min }$ values of the binary mixtures from high to low was NS, DS, and FS, which was the same as that of single particle 


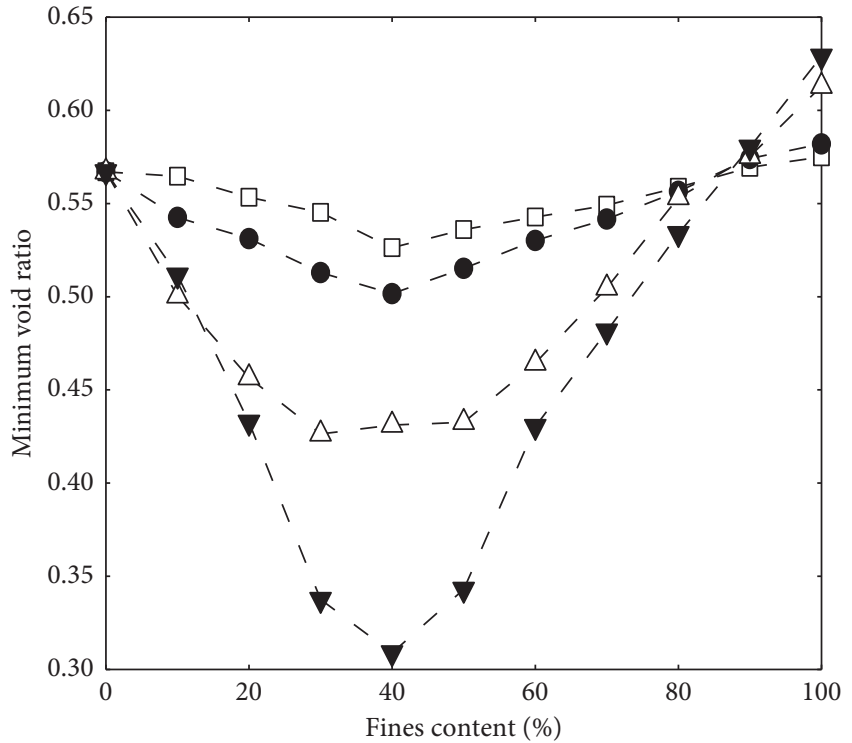

NS

- $-2-5 \mathrm{~mm} \mathrm{\&} 1-2 \mathrm{~mm}$

- $2-5 \mathrm{~mm} \& 0.5-1 \mathrm{~mm}$

$-\triangle 2-5 \mathrm{~mm} \& 0.25-0.5 \mathrm{~mm}$

$-\nabla-2-5 \mathrm{~mm} \& 0.1-0.25 \mathrm{~mm}$

(a)

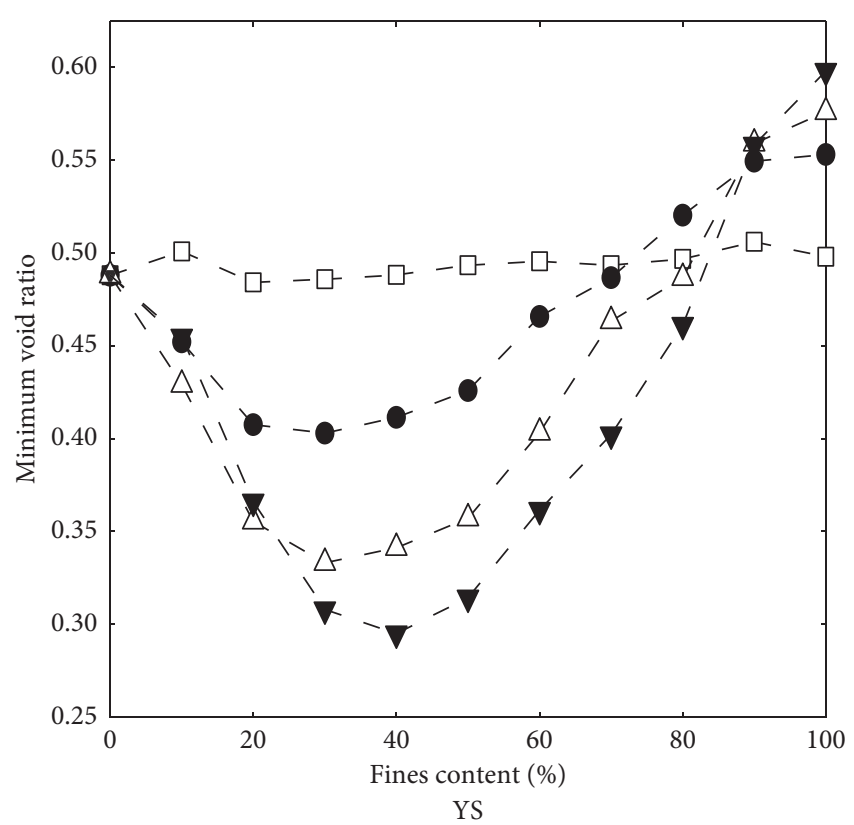

- - 2-5 mm \& 1-2 mm

- $2-5 \mathrm{~mm} \& 0.5-1 \mathrm{~mm}$

$-\triangle 2-5 \mathrm{~mm} \& 0.25-0.5 \mathrm{~mm}$

$-\boldsymbol{\nabla}$ 2-5 mm \& $0.1-0.25 \mathrm{~mm}$

(c)

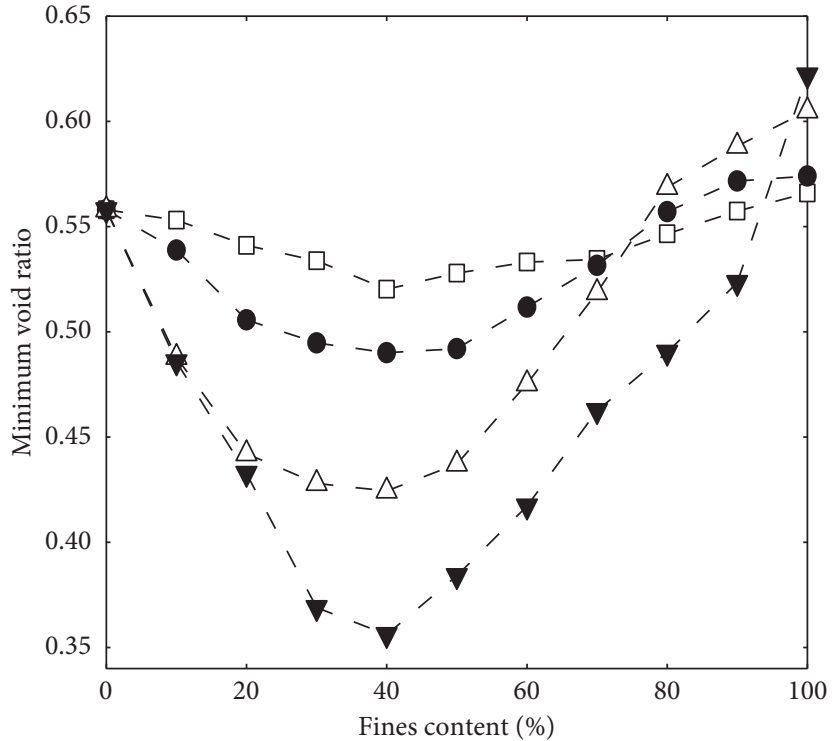

DS

- $-2-5 \mathrm{~mm} \& 1-2 \mathrm{~mm}$

- - $2-5 \mathrm{~mm} \& 0.5-1 \mathrm{~mm}$

$-\triangle 2-5 \mathrm{~mm} \& 0.25-0.5 \mathrm{~mm}$

$-\boldsymbol{\nabla} 2-5 \mathrm{~mm} \& 0.1-0.25 \mathrm{~mm}$

(b)

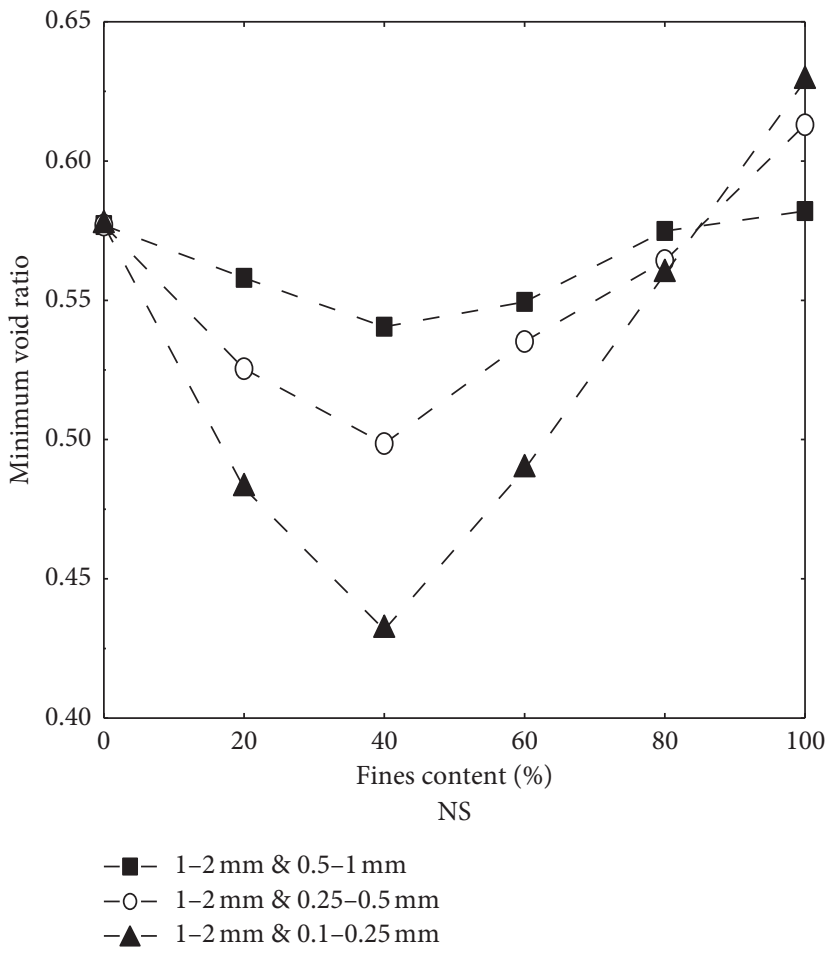




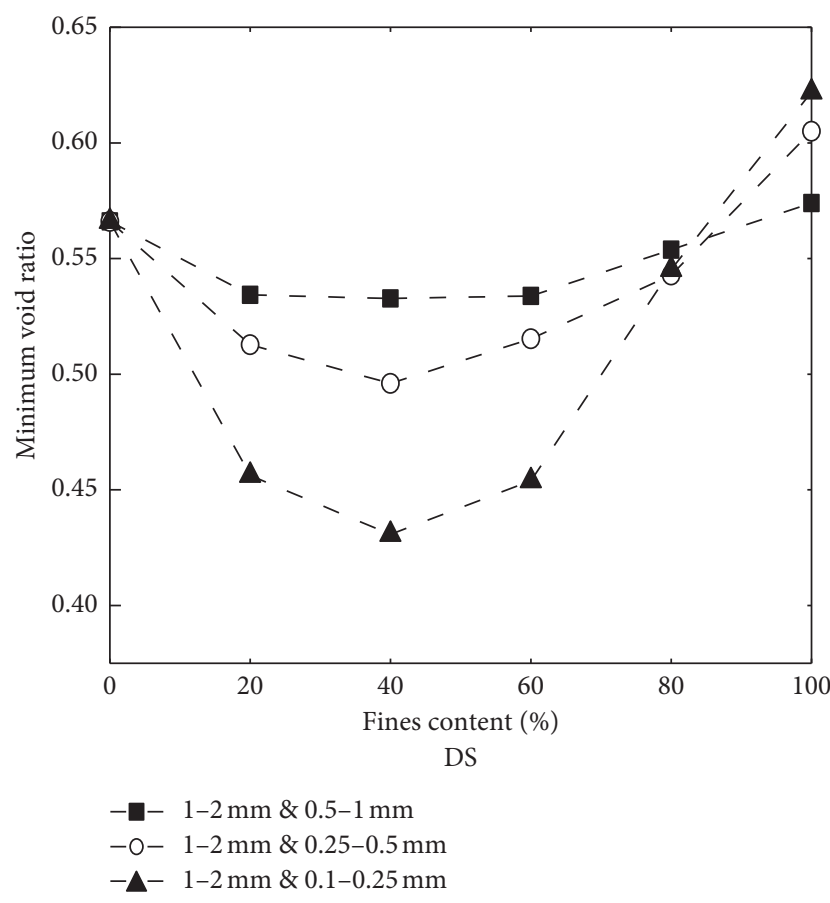

(e)

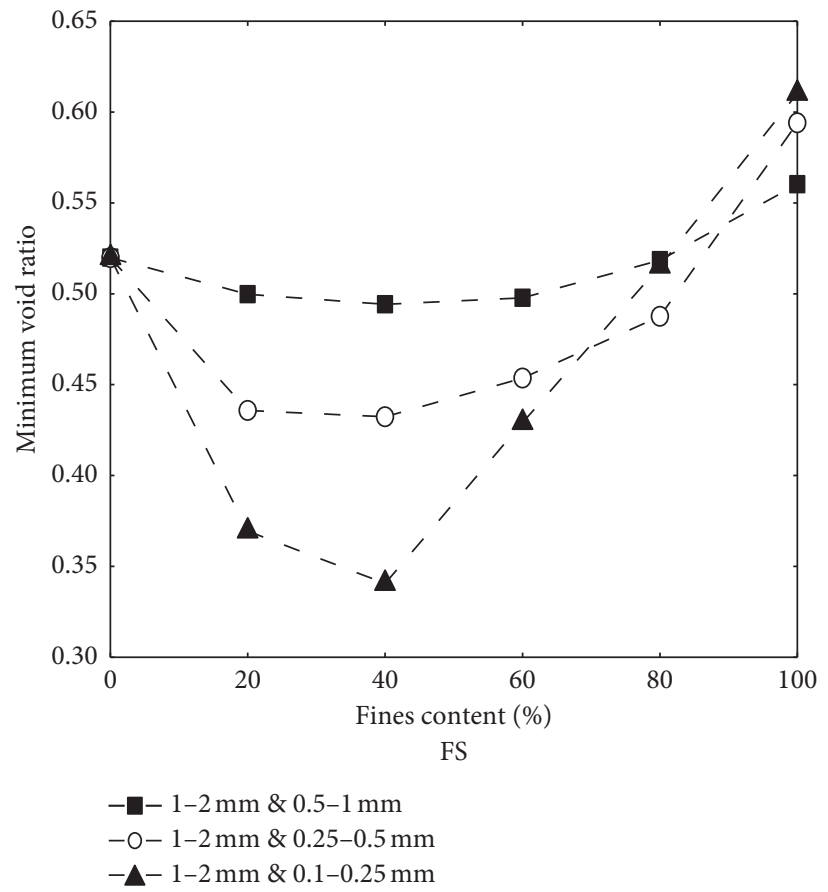

(f)

FIgURE 4: Measured minimum void ratio versus fines content for binary mixtures.

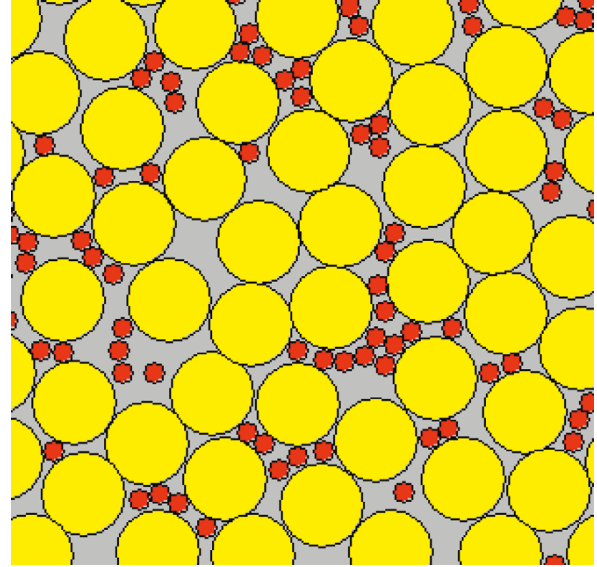

(a)

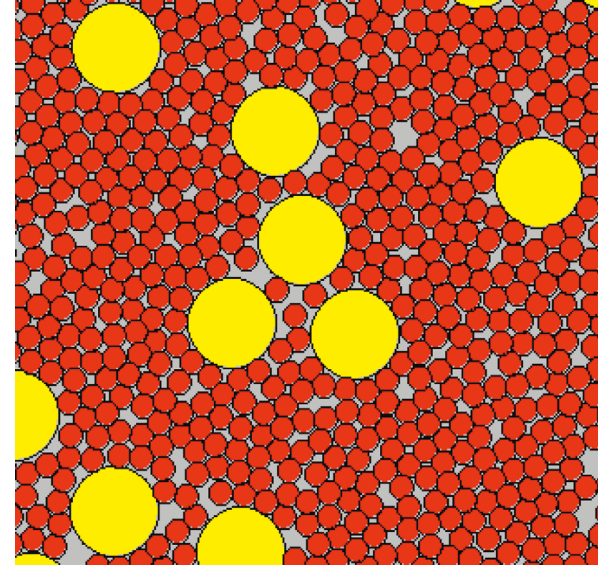

(b)

FIgURe 5: Packing structures for binary packing.

groups. This shows that the minimum void ratio of the sand was closely related to the shapes of the particles, and the smaller the $S$ value of the particle shape parameter, the larger the $e_{\min }$ value.

To further explore the relationship between the $e_{\min }$ values and the $S$ values of the particles, several tests were carried out with alternative materials. In these tests, the steel balls (SB) were mixed with the smaller sized steel balls (SB) and steel cylinders (SC). The $e_{\min }$ values of the binary mixtures of the alternative materials are shown in Figure 9.

As illustrated in Figure 9, the $e_{\min }$ value changed significantly when changing the shape of the fine particles in the binary mixtures. By comparing the results, it can be seen that $e_{\text {min }}$ was smaller when the fine particles were steel balls. This phenomenon further confirms that as $S$ of binary mixtures increased, $e_{\min }$ decreased.

3.4. Preliminary Model for Estimating the Minimum Value of the Minimum Void Ratio. The corresponding changes in $e_{\min }$ with the percentage of the fines content are shown in the above figures. It can be seen that the $e_{\min }$ values decreased in the course of the filling-of-voids process and reached their minimum values when the fines content was about $40 \%$ of the mixture. Furthermore, it can be noted that the $\left(e_{\min }\right)_{\min }$ values of all the binary mixtures were closely related to the particle size differences. 


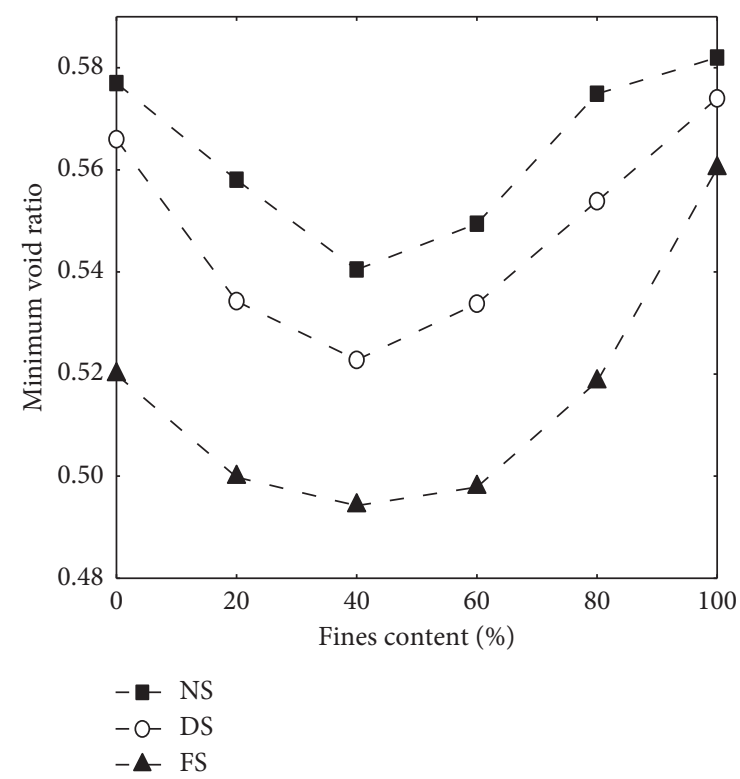

Figure 6: Mixing two groups (1-2 mm and $0.5-1 \mathrm{~mm}$ ).

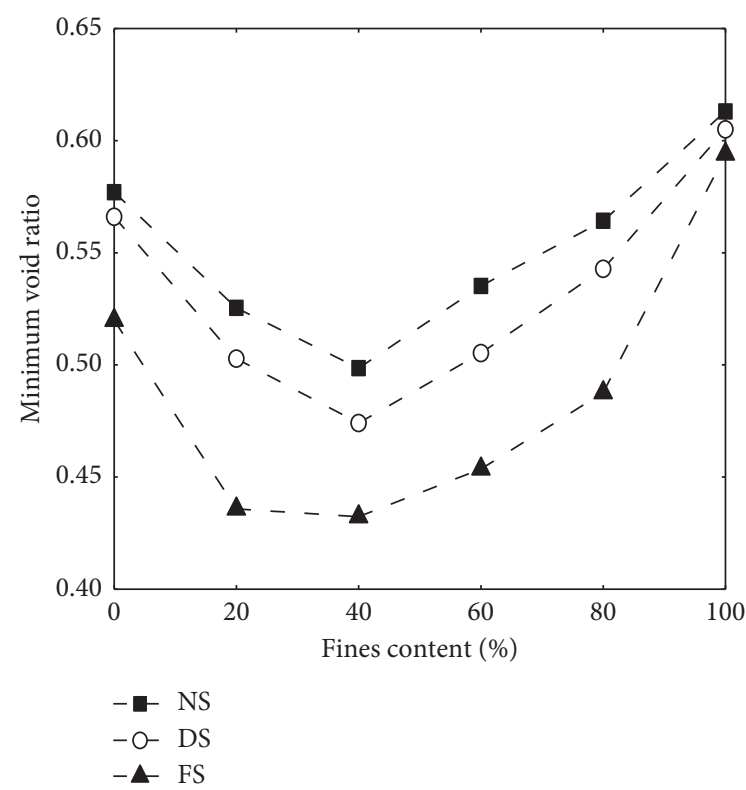

Figure 7: Mixing two groups (1-2 $\mathrm{mm}$ and $0.25-0.5 \mathrm{~mm}$ ).

In order to better explore the effect of the particle size differences for $\left(e_{\min }\right)_{\min }$, the experiments with mixed steel cylinders were performed, and the data were obtained as shown in Figure 10. The fitting curves of $\left(e_{\min }\right)_{\min }$ and $d / D$ for the various types of bimixtures are plotted in Figure 11.

It was obvious that when $d / D$ was near zero, the pores formed by coarse particles were completely filled by the fine particles in an extremely fine state, and $\left(e_{\min }\right)_{\min }$ took an extreme value of zero in ideal status. Therefore, the curve starts from the origin. As shown in Figure 11, the curves for $\left(e_{\min }\right)_{\min }$ and $d / D$ fit the significant relationships of exponential functions for both sand and alternative material mixtures. The fitting results show that the proposed model

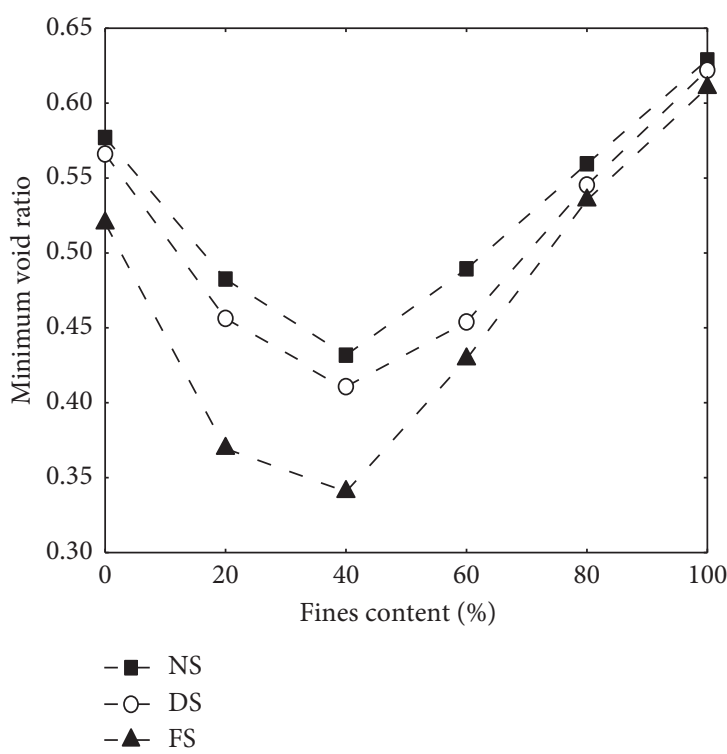

FIgURE 8: Mixing two groups (1-2 mm and $0.1-0.25 \mathrm{~mm})$.

for $\left(e_{\min }\right)_{\min }-\mathrm{d} / D$ was in good agreement with the actual data, with a small deviation.

Equation (1) for $\left(e_{\min }\right)_{\min }$ and $d / D$ was obtained from fitting the curves in Figure 11 using Origin.16 software:

$$
\left(e_{\min }\right)_{\min }=A * \exp \left[-\left(\frac{(d / D)}{T}\right)\right]+y .
$$

Table 4 presents the different values of the parameters $A$, $T$, and $y$ in the above equation for various types of sand and steel shots.

From Table 4, we can see that the coefficient of determination $\left(R^{2}\right)$ was very high, which shows equation (1) can reflect the actual law well. By comparing the values of the three parameters, it can be found that the different values of $A$ and $y$ of different particles were obviously close. Therefore, the parameters $A$ and $y$ can be substituted for by taking the averages of their values for the five kinds of particles. Therefore, equation (1) can be represented by equation (2), as follows.

As shown in Table 4, the regression equation (1) had a better fit for the $\left(e_{\min }\right)_{\min }$ and $d / D$ values, but the three parameters $(y, A, T)$ corresponding to the different mixtures were different. This resulted in different regression equations for each binary mixture, which was very inconvenient for subsequent study. To avoid this inconvenience, it was determined from further analysis of Table 5 that the values of $A$ and $y$ were very close for different binary mixtures. Unlike $A$ and $y$, there were large differences in the $T$ parameters for different mixtures. Thus, $A$ and $y$ could be substituted for with their averages. The corresponding regression equation is shown as follows:

$$
\left(e_{\min }\right)_{\min }=0.54 *\left\{1-\exp \left[-\left(\frac{(d / D)}{T}\right)\right]\right\} .
$$

In order to verify the accuracy of the regression equation $(2)$, the $\left(e_{\min }\right)_{\min }$ values of the different mixtures estimated with equation (2) were compared with the measured values 


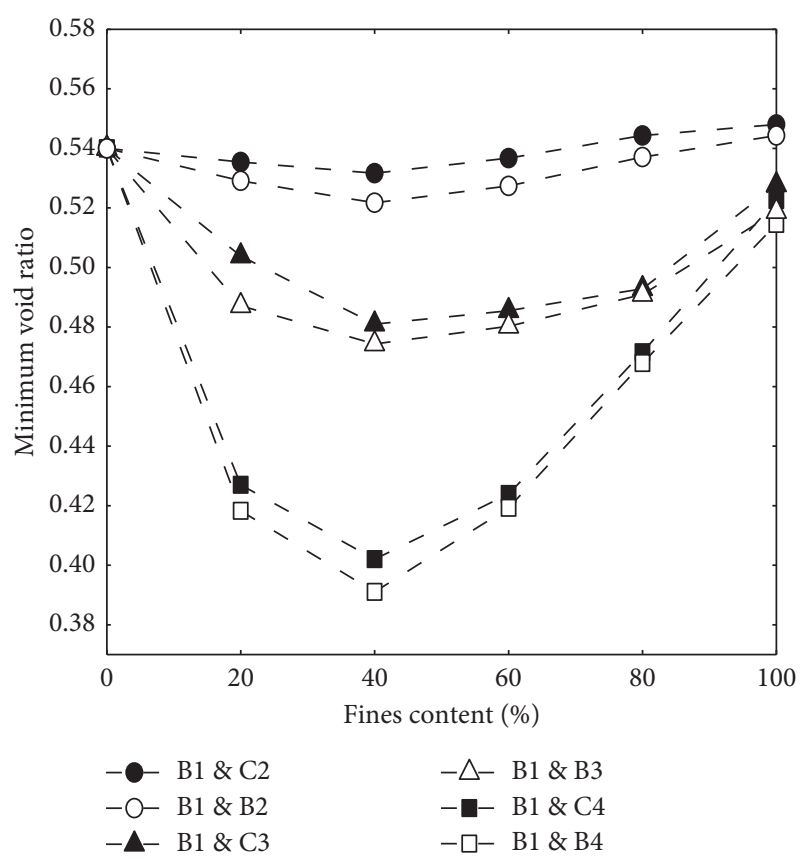

(a)

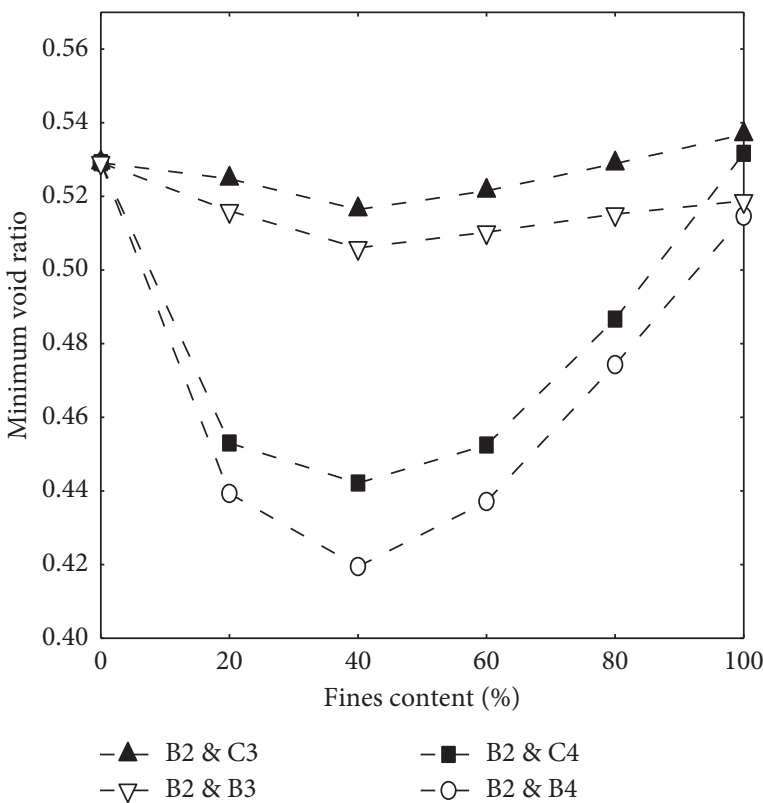

(b)

Figure 9: Measured minimum void ratios versus fines content for alternative material mixtures (SB and SB, and SB and SC).

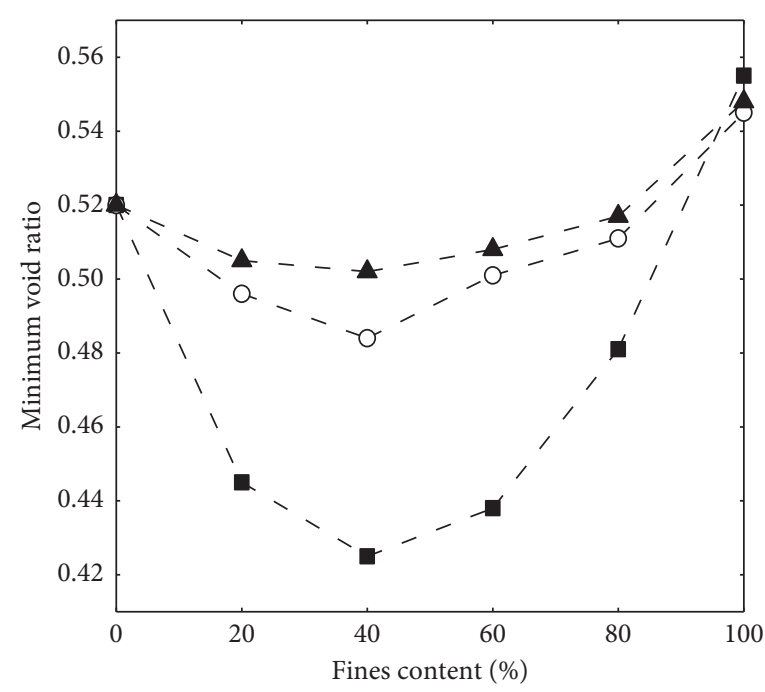

$-\boldsymbol{\Delta}$ C1 \& C2
$-\mathrm{O}-\mathrm{C} 1 \& \mathrm{C} 3$
$-\mathbf{-}-\mathrm{C} 1 \& \mathrm{C} 4$

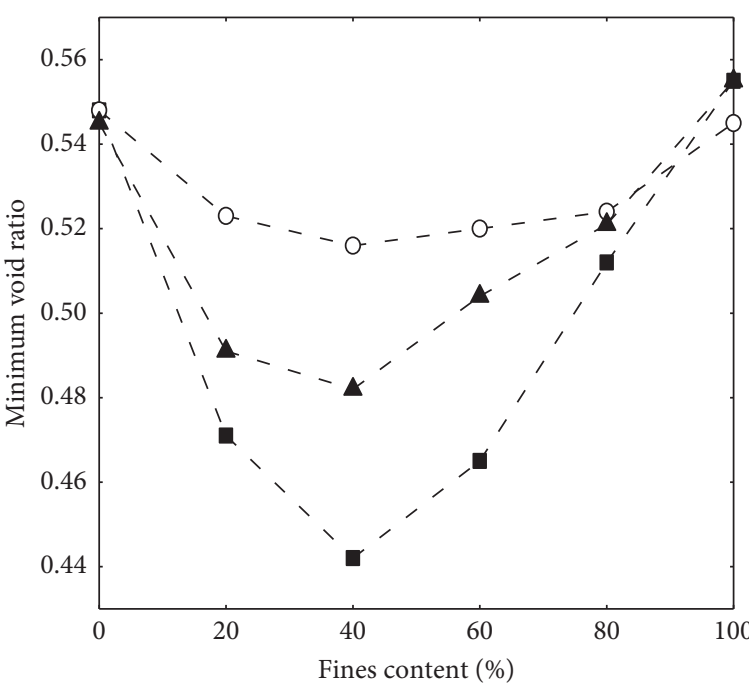

$-\mathrm{O}-\mathrm{C} 2$ \& C3
$-\mathbf{\Delta}-\mathrm{C} 3$ \& C4
$\mathbf{-} \mathbf{-}$ C2 \& C4

(a)

(b)

FIGURE 10: Measured minimum void ratios versus fines content for alternative material mixtures (SC and SC).

in Table 5, as shown in Figure 12. It can be found that the difference between the estimated value and the measured value was small, with the average discrepancy being approximately $3 \%$. Therefore, the new regression equation (2) had a higher accuracy. By combining the particle shape parameters in Tables 3 and 6, it was found that $T$ increased significantly as $S$ of the mixture particles increased. To establish the relationship between $T$ and $S$, the values of $S$ for different particles were compared, as listed in Tables 3, 5, and 6. In Table 7, the sphericity $S$ of the mixture of substituted particles was weighted according to the respective contents of the two particles. Since $\left(e_{\min }\right)_{\min }$ was obtained when the percentage of fines content was approximately $40 \%$, the percentage of fines content was set to $40 \%$ in Table 7. 


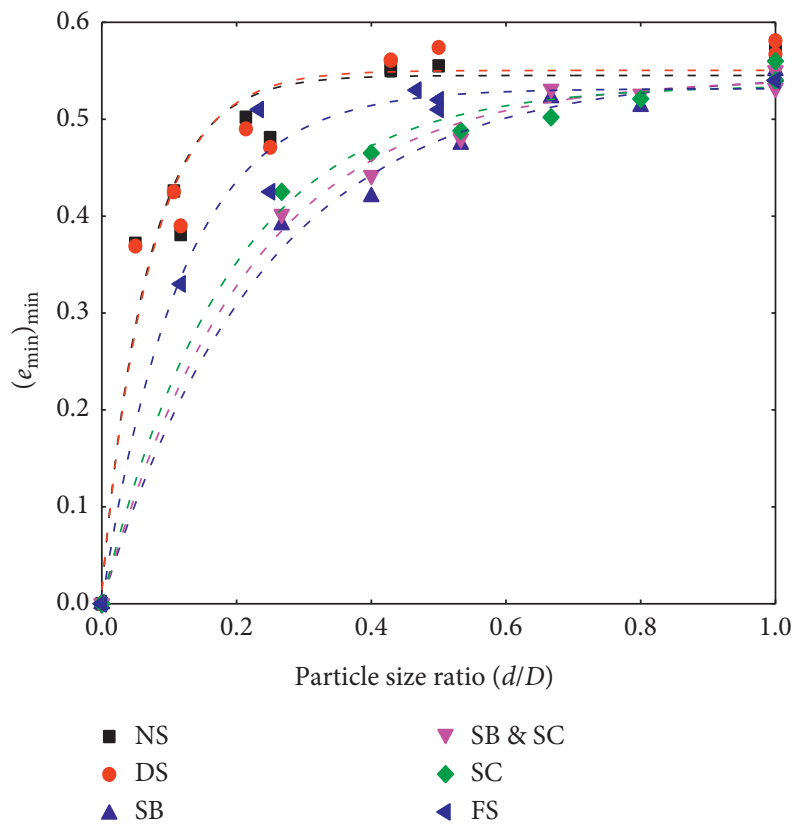

FIGURE 11: The relationship curves of $\left(e_{\min }\right)_{\min }$ and $d / D$ for the binary mixtures.

Table 4: The fitting results of the relationship curve between $\left(e_{\min }\right)_{\min }$ and $d / D$ values.

\begin{tabular}{lccccc}
\hline $\begin{array}{l}\text { Equation } \\
\text { Particle }\end{array}$ & NS & DS & FS & SC & SB \& SC \\
\hline$Y$ & 0.54517 & 0.55037 & 0.53147 & 0.53555 & 0.54283 \\
$A$ & -0.53234 & -0.53633 & -0.53179 & -0.53459 & -0.54198 \\
$T$ & 0.06913 & 0.07206 & 0.11679 & 0.18705 & 0.21647 \\
$R^{2}$ & 0.9563 & 0.95368 & 0.98339 & 0.99397 & 0.54684 \\
\hline
\end{tabular}

TABLE 5: The predicted and the measured values of $\left(e_{\min }\right)_{\min }$.

\begin{tabular}{|c|c|c|c|c|c|c|}
\hline Sands & Mixtures $(\mathrm{mm})$ & $d(\mathrm{~mm})$ & $D(\mathrm{~mm})$ & Equation (2) & Measured & Predicted \\
\hline \multirow{7}{*}{ NS } & $2-5 \sim 0.1-0.25$ & 0.175 & \multirow{4}{*}{3.5} & \multirow{7}{*}{$\left(e_{\min }\right)_{\min }=0.54 *\{1-\exp (-(d / d) / 0.0691)\}$} & 0.305 & 0.278 \\
\hline & $2-5 \sim 0.25-0.5$ & 0.375 & & & 0.426 & 0.425 \\
\hline & $2-5 \sim 0.5-1$ & 0.75 & & & 0.502 & 0.516 \\
\hline & $2-5 \sim 1-2$ & 1.5 & & & 0.550 & 0.539 \\
\hline & $1-2 \sim 0.1-0.25$ & 0.175 & \multirow{3}{*}{1.5} & & 0.425 & 0.440 \\
\hline & $1-2 \sim 0.25-0.5$ & 0.375 & & & 0.517 & 0.525 \\
\hline & $1-2 \sim 0.5-1$ & 0.75 & & & 0.537 & 0.540 \\
\hline \multirow{7}{*}{ DS } & $2-5 \sim 0.1-0.25$ & 0.175 & \multirow{4}{*}{3.5} & \multirow{7}{*}{$\left(e_{\min }\right)_{\min }=0.54 *\{1-\exp (-(d / d) / 0.0721)\}$} & 0.355 & 0.270 \\
\hline & $2-5 \sim 0.25-0.5$ & 0.375 & & & 0.425 & 0.418 \\
\hline & $2-5 \sim 0.5-1$ & 0.75 & & & 0.505 & 0.512 \\
\hline & $2-5 \sim 1-2$ & 1.5 & & & 0.531 & 0.539 \\
\hline & $1-2 \sim 0.1-0.25$ & 0.175 & \multirow{3}{*}{1.5} & & 0.435 & 0.433 \\
\hline & $1-2 \sim 0.25-0.5$ & 0.375 & & & 0.496 & 0.523 \\
\hline & $1-2 \sim 0.5-1$ & 0.75 & & & 0.528 & 0.539 \\
\hline \multirow{3}{*}{ FS } & $1-2 \sim 0.1-0.25$ & 0.175 & \multirow{3}{*}{1.5} & \multirow{3}{*}{$\left(e_{\min }\right)_{\min }=0.54 *\{1-\exp (-(d / d) / 0.1168)\}$} & 0.346 & 0.342 \\
\hline & $1-2 \sim 0.25-0.5$ & 0.375 & & & 0.450 & 0.476 \\
\hline & $1-2 \sim 0.5-1$ & 0.75 & & & 0.503 & 0.533 \\
\hline B1 \& C4 & $3 \sim 0.9$ & 0.9 & \multirow{3}{*}{3} & \multirow{5}{*}{$\left(e_{\min }\right)_{\min }=0.54 *\{1-\exp (-(d / d) / 0.2165)\}$} & 0.402 & 0.405 \\
\hline B1 \& C3 & $3 \sim 1.5$ & 1.5 & & & 0.482 & 0.486 \\
\hline B1 \& C2 & $3 \sim 2.1$ & 2.1 & & & 0.538 & 0.519 \\
\hline B2 \& C3 & $2.1 \sim 1.5$ & 1.5 & \multirow{2}{*}{2.1} & & 0.525 & 0.520 \\
\hline B2 \& C4 & $2.1 \sim 0.9$ & 0.9 & & & 0.452 & 0.466 \\
\hline
\end{tabular}


TABLE 5: Continued.

\begin{tabular}{|c|c|c|c|c|c|c|}
\hline Sands & Mixtures $(\mathrm{mm})$ & $d(\mathrm{~mm})$ & $D(\mathrm{~mm})$ & Equation (2) & Measured & Predicted \\
\hline B1 \& B4 & $3 \sim 0.9$ & 0.9 & \multirow{3}{*}{3} & \multirow{3}{*}{$\left(e_{\min }\right)_{\min }=0.54 *\{1-\exp (-(d / d) / 0.2417)\}$} & 0.385 & 0.384 \\
\hline B1 \& B3 & $3 \sim 1.5$ & 1.5 & & & 0.481 & 0.472 \\
\hline B1 \& B2 & $3 \sim 2.1$ & 2.1 & & & 0.532 & 0.510 \\
\hline $\mathrm{C} 1 \& \mathrm{C} 4$ & $3 \sim 0.9$ & 0.9 & & \multirow{6}{*}{$\left(e_{\min }\right)_{\min }=0.54 *\{1-\exp (-(d / d) / 0.1871)\}$} & 0.422 & 0.431 \\
\hline $\mathrm{C} 1 \& \mathrm{C} 3$ & $3 \sim 1.5$ & 1.5 & 3 & & 0.491 & 0.503 \\
\hline $\mathrm{C} 1 \& \mathrm{C} 2$ & $3 \sim 2.1$ & 2.1 & \multirow{3}{*}{2.1} & & 0.508 & 0.527 \\
\hline $\mathrm{C} 2 \& \mathrm{C} 3$ & $2.1 \sim 1.5$ & 1.5 & & & 0.518 & 0.528 \\
\hline $\mathrm{C} 2 \& \mathrm{C} 4$ & $2.1 \sim 0.9$ & 0.9 & & & 0.440 & 0.485 \\
\hline C3 \& C4 & $1.5 \sim 0.9$ & 0.9 & 1.5 & & 0.482 & 0.518 \\
\hline
\end{tabular}

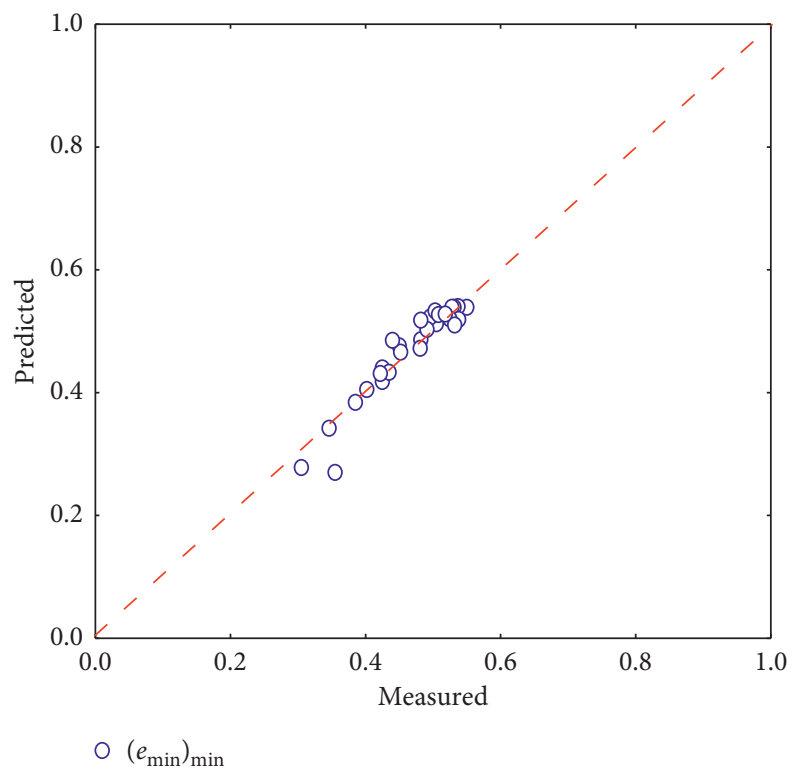

Figure 12: Comparison between the predicted and measured $\left(e_{\min }\right)_{\min }$ using equation (2).

TABLE 6: Descriptions of the alternative materials.

\begin{tabular}{|c|c|c|c|c|}
\hline Particle label & Particle shape & Particle size & Particle photograph & Sphericity \\
\hline B1 & Ball & $\emptyset 3 \mathrm{~mm}$ & & 0.898 \\
\hline B2 & Ball & $ø 2.1 \mathrm{~mm}$ & & 0.887 \\
\hline B3 & Ball & $\emptyset 1.5 \mathrm{~mm}$ & & 0.880 \\
\hline B4 & Ball & $\varnothing 0.9 \mathrm{~mm}$ & & 0.884 \\
\hline $\mathrm{C} 1$ & Cylinder & $ø 3 \mathrm{~mm}, h=2 \mathrm{~mm}$ & & 0.635 \\
\hline $\mathrm{C} 2$ & Cylinder & $ø 2.1 \mathrm{~mm}, h=1.4 \mathrm{~mm}$ & & 0.628 \\
\hline $\mathrm{C} 3$ & Cylinder & $\emptyset 1.5 \mathrm{~mm}, h=1 \mathrm{~mm}$ & $\mathrm{C} 2$ & 0.622 \\
\hline $\mathrm{C} 4$ & Cylinder & $ø 0.9 \mathrm{~mm}, h=0.6 \mathrm{~mm}$ & & 0.619 \\
\hline
\end{tabular}

The fitting curve of $S-T$, as shown in Figure 13, further confirmed that the values of the $T$ and $S$ parameter were closely related. Therefore, it was feasible to obtain the $T$ parameter from the $S$ - $T$ curve. Then the $\left(e_{\min }\right)_{\min }$ values of the binary mixture could be estimated using the $d / D$ values of the two particles and the $T$ value obtained from the $S-T$ curve using equation (2). However, to determine the accurate numerical relationship of the $T$ and $S$ parameters, more particle shapes and particle sizes still needed to be introduced since few types of the particle shapes were included in the test.

\section{Conclusion}

In this experiment, four types of sand and steel shots from different regions were used to explore the relationship between $e_{\min }$ values and particle properties. It was found that for different binary mixtures, the relationships between the $e_{\min }$ values with fines content were similar. Additionally, when the $e_{\min }$ value reaches a minimum, the percentage of corresponding fines content was approximately $40 \%$. The $e_{\min }$ value for the binary sand mixture was significantly related to the particle size ratio and the particle shape, and $e_{\min }$ 
TABLE 7: The weighted sphericity versus the minimum value of the minimum void ratio for the alternative material mixture.

\begin{tabular}{lccc}
\hline Coarsest & Fine particle & Weighted sphericity & $T$ \\
\hline Ball1 & Ball2 & 0.894 & 0.242 \\
Ball1 & Ball3 & 0.891 & 0.242 \\
Ball1 & Ball4 & 0.892 & 0.242 \\
Ball2 & Ball3 & 0.884 & 0.242 \\
Ball2 & Ball4 & 0.886 & 0.242 \\
Ball1 & Cylinder2 & 0.790 & 0.216 \\
Ball1 & Cylinder3 & 0.788 & 0.216 \\
Ball1 & Cylinder4 & 0.786 & 0.216 \\
Ball2 & Cylinder3 & 0.783 & 0.216 \\
Ball2 & Cylinder4 & 0.781 & 0.216 \\
Cylinder1 & Cylinder2 & 0.632 & 0.187 \\
Cylinder1 & Cylinder3 & 0.630 & 0.187 \\
Cylinder1 & Cylinder4 & 0.629 & 0.187 \\
Cylinder2 & Cylinder3 & 0.626 & 0.187 \\
Cylinder2 & Cylinder4 & 0.624 & 0.187 \\
Cylinder3 & Cylinder4 & 0.621 & 0.187 \\
\hline
\end{tabular}

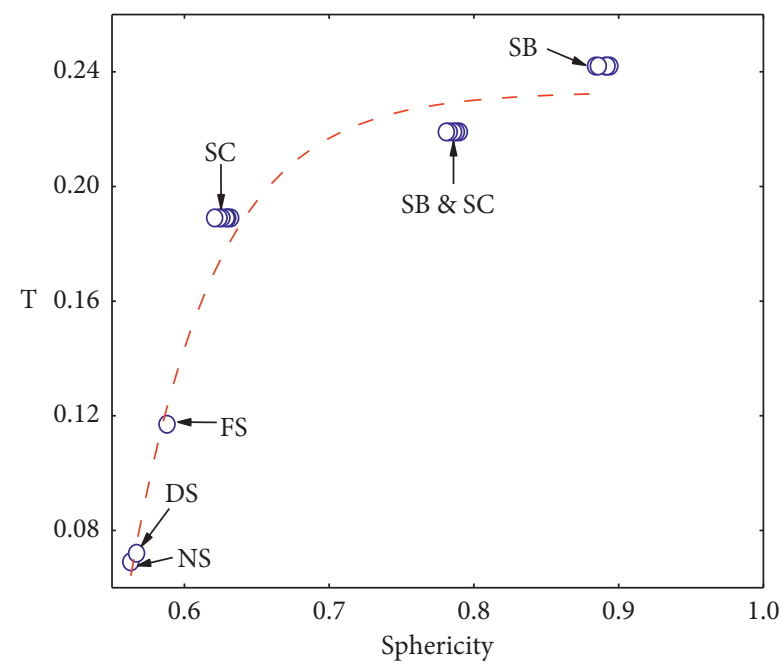

Figure 13: The fitting curve of $S$ - $T$.

decreased with the increase in the particle size difference and the $S$ values of the particles. These conclusions were further verified by the experiments with spherical and cylindrical steel particles.

Based on the experimental data, the functional relationship between $\left(e_{\min }\right)_{\min }$ and $d / D$ was derived for binary mixtures with different particle sizes and shapes. The function could capture the curve shapes of $\left(e_{\min }\right)_{\min }$ versus $d / D$ of soil mixtures well. This proposed model required only one parameter $T$ to predict the $\left(e_{\min }\right)_{\min }$ values for various fines contents. The predicted trends were in good agreement with the measured values. It was found that the $T$ parameter was related to the $S$ value of the constituents of soil mixtures particles. Moreover, the relationship between $T$ and $S$ was preliminarily established. However, both the particle shapes that were available in the experiments and the quantitative descriptions of particle shape data in this essay were relatively inadequate. Therefore, the numerical relationship between $T$ and $S$ needs to be further verified.

\section{Notation}

$e_{\min }: \quad$ Minimum void ratio

$\left(e_{\min }\right)_{\min }:$ Minimum value of minimum void ratio

$C_{\mathrm{u}}: \quad$ Uniformity coefficient

$C_{\mathrm{C}}$ : $\quad$ Coefficient of curvature

$G_{\mathrm{s}}$ : $\quad$ Specific gravity of solid particles

NS: $\quad$ Nanjing River Sand

DS: $\quad$ Dongting Lake Sand

YS: $\quad$ Yizheng Mountain Sand

FS: $\quad$ Fujian Standard Sand

SB: $\quad$ Steel ball

SC: $\quad$ Steel cylinder

$d: \quad$ Fine particle size

$D: \quad$ Coarse particle size

$d / D: \quad$ Particle size ratio

$A, y, T: \quad$ The parameters are obtained by fitting different curves of the minimum value of minimum void ratio and particle size ratio and the parameter $T$ is closely related to the sphericity of the particle

$R^{2}$ : $\quad$ Coefficient of determination.

\section{Data Availability}

The data shown in the tables of the article used to support the findings of this study are included within the article. The data used for the graphs in this article to support the findings of this study are available from the corresponding author upon request.

\section{Conflicts of Interest}

The authors declare that they have no conflicts of interest.

\section{References}

[1] B. Åberg, "Void ratio of noncohesive soils and similar materials," Journal of Geotechnical Engineering, vol. 118, no. 9, pp. 1315-1334, 1992.

[2] K. Miura, K. Maeda, M. Furukawa, and S. Toki, "Physical characteristics of sands with different primary properties," Soils and Foundations, vol. 37, no. 3, pp. 53-64, 1997.

[3] M. M. Toki and G. Ozden, "Compressional behavior of clayey sand and transition fines content," Engineering Geology, vol. 89, no. 3-4, pp. 195-205, 2007.

[4] D. C. Bobei, S. R. Lo, D. Wanatowski, C. T. Gnanendran, and M. M. Rahman, "Modified state parameter for characterizing static liquefaction of sand with fines," Canadian Geotechnical Journal, vol. 46, no. 3, pp. 281-295, 2009.

[5] J. F. Peters and E. S. Berney, "Percolation threshold of sandclay binary mixtures," Journal of Geotechnical and Geoenvironmental Engineering, vol. 136, no. 2, pp. 310-318, 2010.

[6] T. C. Powers, The Properties of Fresh Concrete, John Wiley \& Sons, New York, USA, 1968.

[7] J. S. Reed, Principles of Ceramics Processing, John Wiley \& Sons, New York, USA, 2nd edition, 1995.

[8] L. N. Smith, A Knowledge-Based System for Powder Metallurgy Technology, Professional Engineering Publishing Ltd., London and Bury St. Edmunds, UK, 2003.

[9] M. Cubrinovski and K. Ishihara, "Maximum and minimum void ratio characteristics of sands," Soils and Foundations, vol. 42, no. 6, pp. 65-78, 2002. 
[10] G.-C. Cho, J. Dodds, and J. C. Santamarina, "Particle shape effects on packing density, stiffness, and strength: natural and crushed sands," Journal of Geotechnical and Geoenvironmental Engineering, vol. 132, no. 5, pp. 591-602, 2006.

[11] A. R. Fuggle, M. M. Roozbahani, and J. D. Frost, "Size effects on the void ratio of loosely packed binary particle mixtures," in Proceedings of the Geo-Congress 2014: Technical Papers, pp. 129-138, Atlanta, Georgia, February 2014.

[12] J. C. Santamarina and G. C. Cho, "Soil behaviour: the role of particle shape," in Advances in Geotechnical Engineering: The Skempton Conference, R. J. Jardine, D. M. Potts, and K. G. Higgins, Eds., vol. 1, pp. 604-617, Thomas Telford, London, UK, 2004.

[13] T. L. Youd, Factors Controlling Maximum and Minimum Densities of Sands, ASTM Special Technical Publication, West Conshohocken, PA, USA, 1973.

[14] S.-S. Li, D.-Y. Li, and Y.-F. Gao, "Determination of maximum and minimum void ratios of sands and their influence factors," Chinese Journal of Geotechnical Engineering, vol. 40, no. 3, pp. 554-561, 2018.

[15] A. Kezdi, Soil Physics: Selected Topics, Elsevier Scientific Publishing Company, Amsterdam, Netherlands, 1979.

[16] M. Cubrinovski and K. Ishihara, "Maximum and minimum void ratio characteristics of sands," Journal of the Japanese Geotechnical Society, vol. 42, no. 6, pp. 65-67, 2008.

[17] C. S. Chang and Z.-Y. Yin, "Micromechanical modeling for behavior of silty sand with influence of fine content," International Journal of Solids and Structures, vol. 48, no. 19, pp. 2655-2667, 2011.

[18] C. S. Chang, J.-Y. Wang, and L. Ge, "Modeling of minimum void ratio for sand-silt mixtures," Engineering Geology, vol. 196, pp. 293-304, 2015.

[19] C. S. Chang, J. Y. Wang, and L. Ge, "Maximum and minimum void ratios for sand-silt mixtures," Engineering Geology, vol. 211, pp. 7-18, 2016.

[20] S.-P. Yu, M.-C. Wang, and M.-H. Hon, “The dependence of properties of alumina-zirconia-graphite refractories on particle size distribution by furnas model," Japanese Journal of Applied Physics, vol. 38, no. 11, pp. 6433-6437, 1999.

[21] K. Shinohara, M. Oida, and B. Golman, "Effect of particle shape on angle of internal friction by triaxial compression test," Powder Technology, vol. 107, no. 1-2, pp. 131-136, 2000.

[22] A. K. Ashmawy, B. Sukumaran, and V. V. Hoang, "Evaluating the influence of particle shape on liquefaction behavior using discrete element modeling," in Proceedings of the Thirteenth International Offshore and Polar Engineering Conference, pp. 542-549, Honolulu, HI, USA, May 2003.

[23] A. M. Sallam and A. K. Ashmawy, "Effect of particle shape and angularity on dilation of granular soils: a discrete element approach," in Proceedings of the 17th International Conference on Soil Mechanics \& Geotechnical Engineering: The Academia \& Practice of Geotechnical Engineering, Alexandria, Egypt, October 2009.

[24] P. C. Rousé, R. J. Fannin, and D. A. Shuttle, "Influence of roundness on the void ratio and strength of uniform sand," Géotechnique, vol. 58, no. 3, pp. 227-231, 2008.

[25] J. Yang and L. M. Wei, "Collapse of loose sand with the addition of fines: the role of particle shape," Géotechnique, vol. 62, no. 12, pp. 1111-1125, 2012.

[26] J. Yang and X. D. Luo, "Exploring the relationship between critical state and particle shape for granular materials," Journal of the Mechanics \& Physics of Solids, vol. 84, pp. 196-213, 2015.
[27] L. M. Wei and J. Yang, "On the role of grain shape in static liquefaction of sand-fines mixtures," Géotechnique, vol. 64, no. 9, pp. 740-745, 2014.

[28] F. N. Altuhafi, M. R. Coop, and V. N. Georgiannou, "Effect of particle shape on the mechanical behavior of natural sands," Journal of Geotechnical and Geoenviremental Engineering, vol. 142, no. 12, article 04016071, 2016.

[29] A. Cherif Taiba, M. Belkhatir, A. Kadri, Y. Mahmoudi, and T. Schanz, "Insight into the effect of granulometric characteristics on the static liquefaction susceptibility of silty sand soils," Geotechnical and Geological Engineering, vol. 34, no. 1, pp. 367-382, 2016.

[30] M. L. Hentschel and N. W. Page, "Selection of descriptors for particle shape characterization," Particle \& Particle Systems Characterization, vol. 20, no. 1, pp. 25-38, 2003.

[31] C. F. Mora and A. K. H. Kwan, "Sphericity, shape factor, and convexity measurement of coarse aggregate for concrete using digital image processing," Cement and Concrete Research, vol. 30, no. 3, pp. 351-358, 2000. 


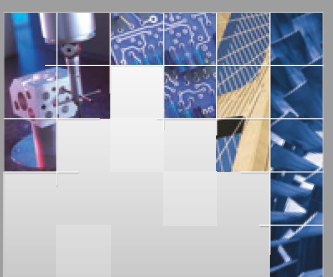

\section{Enfincering}
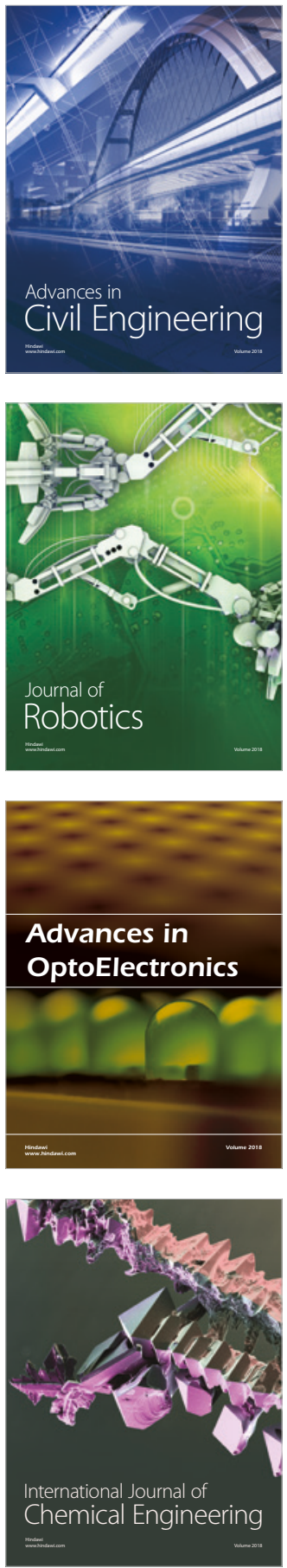

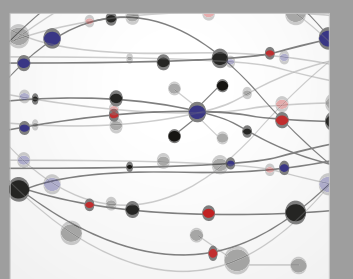

\section{Rotating \\ Machinery}

The Scientific World Journal

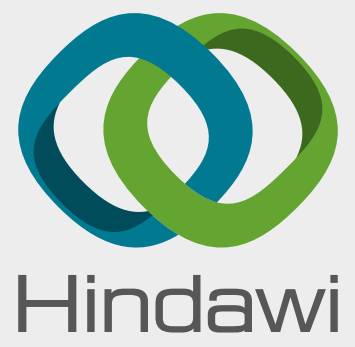

Submit your manuscripts at

www.hindawi.com
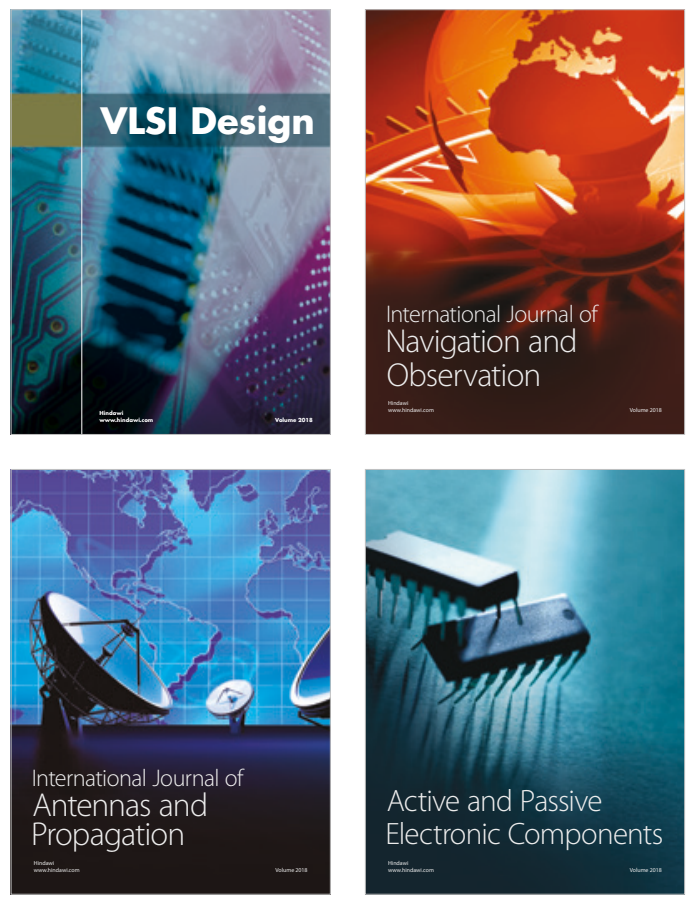
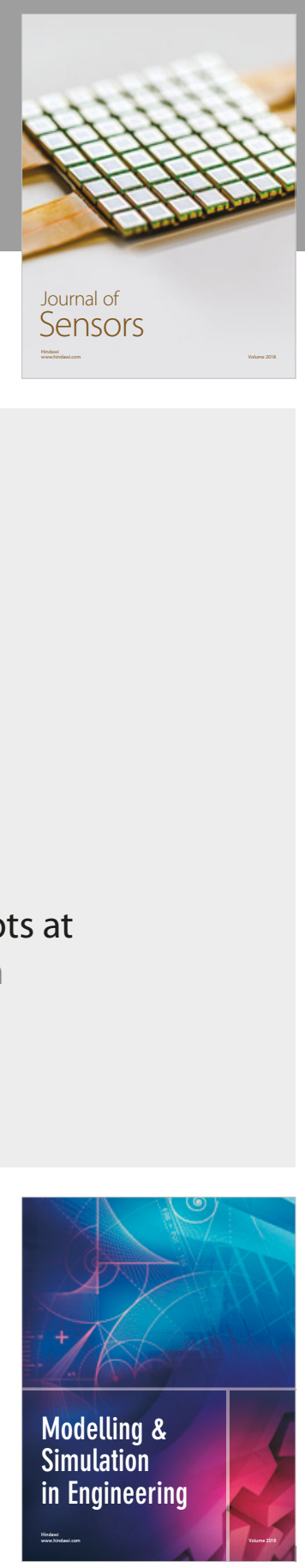

\section{Advances \\ Multimedia}
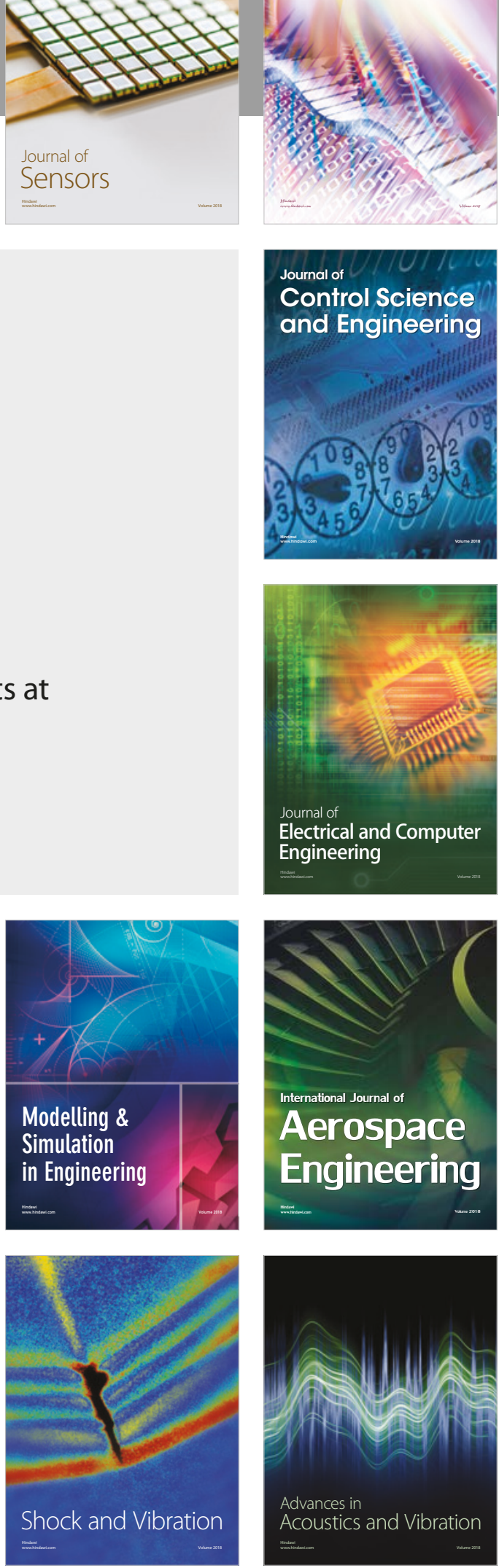